\title{
Effect of Different Core Exercises Applied During the Season on Strength and Technical Skills of Young Footballers
}

\author{
Özhan Bavlı ${ }^{1}$, Caner Batuhan Koç ${ }^{1}$ \\ ${ }^{1}$ Faculty of Sport Science, Çanakkale Onsekiz Mart University, Çanakkale, Turkey \\ Correspondence: Özhan Bavlı, Faculty of Sport Science, Çanakkale Onsekiz Mart University, Terzioğlu Campus, 17100, \\ Çanakkale, Turkey.
}

Received: March 12, 2018

Accepted: March 25, $2018 \quad$ Online Published: March 29, 2018

doi:10.11114/jets.v6i5.3101

URL: https://doi.org/10.11114/jets.v6i5.3101

\begin{abstract}
The aim of this study is to investigate the effect of two different types of core training applied during the season on the strength performance and football technical skills of young footballers. A total of 18 footballers average age was $15 \pm 0.8$ years voluntarily participated in the study. Two different core trainings were applied in addition to football technical skills. Before and after the study, the sit-up, standing long jump, push-up, dribbling, passing and shooting performances of players were observed. Data were assessed with the SPSS. In the dynamic group there were statistically significant improvements in all variables apart from shooting and passing, while the static group had statistically significant development of all variables apart from shooting. The control group only had statistically significant development for sit-up performance. While development sufficient to form significant differences between the variables observed in the experimental groups was not observed, there were significant differences for all variables when compared with the control group apart from shooting performance. In conclusion, footballers with eight-week dynamic and static core training added to in-season football training had similar levels of development in terms of strength and football technical skills, with significant development of strength, dribbling and passing skills when compared to a group without core training. In light of this data, eight-week dynamic and static strength training applied to footballers in the development period may be said to be an effective method to develop abdominal muscle strength and explosive strength performance and to develop dribbling and passing skills unique to football.
\end{abstract}

Keywords: sport, football, strength, training, technical skills

\section{Introduction}

Football, or soccer, is a team game popular around the world with participants of all ages. The increasing competition between teams and search for new stars has lowered the age of discovering new footballers. Training applied to individuals learning the sport at an early age significantly affects what type of star they will be in the future. Effective construction of sudden direction changes, jumps and kicks within the game of football determines a player's success. The success of these skills is affected by the strength, speed, balance and quickness traits of a player. While development of these traits is planned in the period before the season, due to intensified matches during the season and an intensified training plan, training aims to develop technical and tactical skills and preserve other performance traits. When the exercise model to preserve these performance elements and develop technical skills within the season are considered, core exercises may be chosen. Core exercises may be chosen by trainers as they increase sporting performance, reduce the risk of injury and aid in more balanced development of sporting skills (Hedrick 2000, McCurdy et al. 2005).

When strength training is applied correctly in a planned form, it has been determined to have positive effects on individuals in the development period (Falk and Tenenbaum 1996, Ramsay et al. 1990, Blimkie 1993, Faigenbaum et al. 1993, Faigenbaum et al. 1996). However, sufficient studies researching the effect of strength training on football technical skills among sportspeople in the development period have not been completed. As a result, this study was completed with the aim of researching the effect of two different strength training models - dynamic and static core exercises - on strength performance and football technical skills of footballers in the development period.

\section{Method}

Participants: The study included 18 male amateur footballers average age was $15 \pm 0.8$ years, with at least two years football license and no health problems who volunteered to participate. 
Procedure: Players were randomly divided into 3 groups (dynamic: 6, static: 6, control: 6). Players had football technical training (45 min) applied for eight weeks (3 days per week); however, in the experimental groups two different strength training of dynamic strength and static strength training were applied, in addition to football training. Before and after the study, the sit-up, standing long jump, push-up and football technical skills of players were tested. Before beginning the study, players and their parents provided a consent form asserting they were voluntarily participating in the study.

All participants signed an informed consent form before the beginning of the study, which was approved by the Human Ethics Committee of the Canakkale Onsekiz Mart University and conducted in accordance with the Declaration of Helsinki, good clinical practices, and applicable laws and regulations.

Football Training program; $45 \mathrm{~min}$ : $5 \mathrm{~min}$ warm-up, $35 \mathrm{~min}$ exercises related to dribbling, passing, defense and offensive work and 5 min cool-down.

Static Strength training: $30 \mathrm{~min}$, including trunk and leg static exercises, with increasing loading over time, two days per week with holds of 30-60 s x 2 sets with 2-5 min rest periods.

Dynamic strength training: $30 \mathrm{~min}$, including leg and trunk lifting exercises and increasing loading over time, two days per week with 20-40 repetitions x 2 sets with 2-5 min rest periods.

Table 1. Strength Training Program

\begin{tabular}{llllllllll}
\hline Group & Exercises & 1st wk & 2nd wk & 3rd wk & 4 th wk & 5 th wk & 6th wk & 7 th wk & 8 th wk \\
\hline Dynamic & Single leg lift & $25 \times 2$ & $25 \times 2$ & $30 \times 2$ & $30 \times 2$ & $35 \times 2$ & $35 \times 2$ & $40 \times 2$ & $40 \times 2$ \\
(repeat x set) & Double leg lift & $25 \times 2$ & $25 \times 2$ & $30 \times 2$ & $30 \times 2$ & $35 \times 2$ & $35 \times 2$ & $40 \times 2$ & $40 \times 2$ \\
& Sit-up & $25 \times 2$ & $25 \times 2$ & $30 \times 2$ & $30 \times 2$ & $35 \times 2$ & $35 \times 2$ & $40 \times 2$ & $40 \times 2$ \\
& Reverse sit-up & $25 \times 2$ & $25 \times 2$ & $30 \times 2$ & $30 \times 2$ & $35 \times 2$ & $35 \times 2$ & $40 \times 2$ & $40 \times 2$ \\
\hline Static & Plank & $30 \times 2$ & $30 \times 2$ & $40 \times 2$ & $40 \times 2$ & $50 \times 2$ & $50 \times 2$ & $60 \times 2$ & $60 \times 2$ \\
(second x set ) & Side plank & $30 \times 2$ & $30 \times 2$ & $40 \times 2$ & $40 \times 2$ & $50 \times 2$ & $50 \times 2$ & $60 \times 2$ & $60 \times 2$ \\
& V-hold & $30 \times 2$ & $30 \times 2$ & $40 \times 2$ & $40 \times 2$ & $50 \times 2$ & $50 \times 2$ & $60 \times 2$ & $60 \times 2$ \\
& Bridge & $30 \times 2$ & $30 \times 2$ & $40 \times 2$ & $40 \times 2$ & $50 \times 2$ & $50 \times 2$ & $60 \times 2$ & $60 \times 2$ \\
\hline
\end{tabular}

Sit-up performance measurement; maximum number of repetitions in 1 min duration, with knees bent and hands on the back of the neck.

Standing long jump measurement; maximum distance forward from a single jump with both feet flat at the starting point.

Push-up measurement; Maximum number of repetitions in push-up position in $30 \mathrm{~s}$.

Football skills test; The Mor \& Christian football skills test comprising passing, shooting and dribbling skills was applied (Mor and Christian 1979).

Dribble test; time for the player to slalom the ball around 12 obstacle cones at $4.5 \mathrm{~m}$ intervals around an $18 \mathrm{~m}$ diameter circle back to the starting point in seconds.

Shoot test; Obstacles of 4 round shapes with $1.21 \mathrm{~m}$ diameter are the goals. The player shoots at each of the 4 obstacles from $14.5 \mathrm{~m}$ distance 4 times. Accurate target is 10 points, missed target is 4 points. Total points are recorded after the tests.

Pass test; The ball is hit from $13.5 \mathrm{~m}$ distance from 3 points, 4 times to pass between cones placed at $91 \mathrm{~cm}$ from each other. Each target is 1 point, with total successful passes recorded.

Statistical analysis: Data had pretest and posttest analysis performed with the one-way ANOVA test, as the Shapiro-Wilk test was negative, in the SPSS program. For analysis of differences between the pretest and posttest points in the groups, the Kruskal Wallis analysis was used as the Shapiro-Wilk test was significant. Results with p<0.05 were accepted as significant.

\section{Results}

Table 2. Demographic characteristics of participants $(\mathrm{x} \pm \mathrm{sd})$

\begin{tabular}{lllll}
\hline Group & Age (year) & Height $(\mathbf{c m})$ & Weight $(\mathbf{k g})$ & Sporting age (year) \\
\hline Dynamic & $15 \pm 0.8$ & $169 \pm 6.4$ & $66.6 \pm 2.1$ & $6 \pm 0.8$ \\
Static & $15 \pm 0.8$ & $165.1 \pm 2.8$ & $64.4 \pm 3.6$ & $6 \pm 0.8$ \\
Control & $15 \pm 0.8$ & $166.5 \pm 2.7$ & $66.1 \pm 4.1$ & $6 \pm 0.8$ \\
F & 0.000 & 1.199 & 0.659 & 0.000 \\
P & 1.000 & 0.329 & 0.532 & 1.000 \\
\hline
\end{tabular}


The findings related to demographic characteristics of players in the study groups are shown in Table 2. One-way ANOVA comparing the demographic characteristics of the groups showed that there were no significant differences between the groups in terms of demographics $(\mathrm{p}<0.05)$.

Table 3. Pretest-posttest results for strength tests $(x \pm s d)$

\begin{tabular}{lllllll}
\hline Group & \multicolumn{2}{l}{ Sit-up (repetitions) } & \multicolumn{2}{l}{ Push-up (repetitions) } & \multicolumn{2}{l}{ Long jump (cm) } \\
\cline { 2 - 7 } & Pretest & Posttest & Pretest & Posttest & Pretest & Posttest \\
Dynamic & $21.1 \pm 1.3$ & $29.3 \pm 2.4^{*}$ & $29.6 \pm 2.6$ & $36.1 \pm 2.1^{*}$ & $227.5 \pm 9.2$ & $230.3 \pm 8.6^{*}$ \\
Static & $20.3 \pm 2.7$ & $27.5 \pm 2.5^{*}$ & $29.5 \pm 3.2$ & $36.1 \pm 4.1^{*}$ & $221.1 \pm 4.5$ & $225 \pm 5.3^{*}$ \\
Control & $20.5 \pm 1.3$ & $22.6 \pm 2.3 *$ & $29.8 \pm 1.9$ & $31.6 \pm 2.8$ & $219.1 \pm 2.8$ & $220.3 \pm 3.5$ \\
F & 0.314 & 11.839 & 0.023 & 4.190 & 2.993 & 3.908 \\
P & 0.735 & $\mathbf{0 . 0 0 1} * *$ & 0.977 & $\mathbf{0 . 0 3 6}^{* *}$ & 0.081 & $\mathbf{0 . 0 4 0} * *$ \\
\hline
\end{tabular}

*Significant difference between pretest-posttest, $* *$ Significant difference between study groups

The pretest-posttest measurements for strength performance of the players in the study groups are shown in Table 3 . When pretest results are noted, there were no significant differences between the study groups in terms of all strength tests. After eight weeks of strength training, the players with dynamic and static strength training had significant variation in sit-up, push-up and long jump performance compared to before the study $(\mathrm{p}<0.05)$. The control group with only football training only showed significant variation in sit-up performance $(\mathrm{p}<0.05)$. Comparison of the variation in pretest-posttest measurements in the study groups found no significant difference between players in the dynamic and static strength training groups, with a significant variation in all strength performances between the two study groups and the control group $(\mathrm{p}<0.05)$.

Table 4. Pretest-posttest results for football skills ( $\mathrm{x} \pm \mathrm{sd})$

\begin{tabular}{lllllll}
\hline \multirow{2}{*}{ Group } & \multicolumn{2}{l}{ Shoot (points) } & \multicolumn{2}{l}{ Dribbling (s) } & \multicolumn{2}{l}{ Pass (points) } \\
\cline { 2 - 7 } & Pretest & Posttest & Pretest & Posttest & Pretest & Posttest \\
\hline Dynamic & $137 \pm 14.9$ & $141 \pm 12.8$ & $21.4 \pm 0.5$ & $20.9 \pm 0.4^{*}$ & $8.8 \pm 2.3$ & $10.5 \pm 1.1$ \\
Static & $131 \pm 17.1$ & $141 \pm 8.8$ & $21.3 \pm 0.8$ & $20.5 \pm 0.8^{*}$ & $8.5 \pm 1.5$ & $10.6 \pm 1.1^{*}$ \\
Control & $134 \pm 6.1$ & $136 \pm 6.5$ & $21.8 \pm 0.8$ & $21.7 \pm 0.8$ & $7 \pm 0.1$ & $7.8 \pm 1.6$ \\
F & 0.292 & 0.525 & 0.797 & 5.386 & 1.776 & 9.613 \\
P & 0.751 & 0.602 & 0.469 & $\mathbf{0 . 0 1 7 * *}$ & 0.203 & $\mathbf{0 . 0 0 2 * *}$ \\
\hline
\end{tabular}

*Significant difference between pretest-posttest, ${ }^{* *}$ Significant difference between study groups

The findings related to football skill pretest-posttest measurements according to study group are shown in Table 4 . When pretest measurements are noted, there were no significant differences between the study groups in terms of points for all football skill tests. Contrary to this, after eight weeks of strength training, there was a significant variation in dribbling skills among players with dynamic strength training. There were significant variations in dribbling and passing skills of players with static strength training. In the control group with only football training, there was no significant variation in football skills at the end of the study. Comparison of the variation in study groups on pretest and posttest measurements found no significant difference between the dynamic and static strength training players, but both study groups were significantly different to the control group in terms of dribbling and passing performance $(\mathrm{p}<0.05)$.

\section{Discussion}

The aim of this study was to investigate the effect of two different strength trainings added to football technical training for eight weeks on the strength and football technical skills of young footballers. The players were divided into two experimental and one control group and participated in a 75 min training period, 3 days per week. At the end of the study players participating in both types of strength training showed significant development of sit-up, push-up and long jump performance compared to players without strength training. Additionally, there was significant variation in the dribbling and passing skills from among football technical skills for players participating in strength training, with significant development in terms of dribbling skills of players with strength training compared to those without strength training. It is commonly reported in previous studies that different resistance training types have positive effects on the motor skills of footballers like speed (Brito et al. 2014 ,Meylan and Malatesta 2009, Christou et al.2006), strength (Brito et al. 2014, Jay et al. 2004, Christou et al.2006), quickness (Meylan and Malatesta 2009, Christou et al.2006), stamina (Helgerud et al. 2001) and balance (Iacono et al. 2016, Sever 2017, Taskin 2016, Yildizer and Kirazci 2017). Contrary to this, when the limited studies investigating the effect of this type of training on the technical skills of footballers are examined, it was found that speed and jumping work applied during the season had a positive effect on kicking skills of footballers (marques et al. 2013, Sedano et al. 2009, Villarreal et al. 2015, Haghighi et al. 2012, Manolopoulos et al. 2004).

While studies in the literature have focused on the variation in shooting skills after exercise in football, this study observed passing and dribbling skills in addition to shooting skills. Previous studies have presented findings that resistance exercises 
positively developed shooting skills. However, in this study when the pretest and posttest points for shooting skills of players with strength training are compared, there was no significant difference found. The reason for this finding, different to the literature, may be that previous studies applied maximum strength, plyometric and isokinetic training models designed for the lower extremity muscles as strength training. The type of strength training chosen may have developed shooting skills by affecting leg strength. In this study, strength training related to the core region (hip, back and abdomen) was chosen.

The core region is reported to be the area effective in transferring power gained from the ground to the muscles and motion of the upper region of the body. Additionally, it was identified that strong core region muscles are required to reduce the risk of injury during exercise and for more balanced movements (Behm et al. 2005, Anderson and Behm 2005, Marshall and Murphy 2005). In studies investigating the correlation between core exercises and sporting performance, sportspeople with core training were not identified to have positive development in sporting performance (Stanton et al. 2004, Tse et al. 2005, Nesser et al. 2008). Contrary to this, there are research results reporting that adding core training to football training significantly developed strength and power (Brito et al. 2010, Daneshjoo et al. 2012). The causes of these differences in study results may be that studies were applied in different branches like swimming, rowing, and football and that branch-specific techniques may affect power production during movement. There is a great need to investigate the effects of core exercises on a single sports branch. This study found that adding core exercises to football training significantly developed sit-up, push-up and explosive strength traits. This is the first study investigating the effect of core exercises on football skills and while there was no significant effect of core exercises on shooting skills at the end of training, it was determined to have a significant positive effect on other important skills in football of dribbling and passing. Considering that shooting skills are affected by muscle strength in the lower extremities, it may be said to be an expected result that core exercises which do not work this region do not affect shooting skills. However, the effects of applying a variety of durations and types of core exercises may comprise research questions for future studies.

At the end of the study, eight static and dynamic core exercises added to weekly in-season football technical training were determined to have similar positive effects on the sit-up, push-up and explosive strength of young footballers. These types of exercises may be added to training during the season for strength development of young footballers. However, adding these types of exercises to in-season training to develop the football-specific passing and dribbling skills may not have the expected positive effect on dribbling skills.

\section{References}

Anderson, K., \& Behm, D. G. (2005). The impact of instability resistance training on balance and stability. Sports Medicine, 35, 43-53, PMID:15651912

Behm, D. G., Leonard, A. M., Young, W. B., Bonsey, W. A. C., \& Mackinnon, S. N. (2005). Trunk muscle electromyographic activity with unstable and unilateral exercises. J. Strength Cond. Res., 19, 193-201. https://doi.org/10.1519/1533-4287(2005)19<193:TMEAWU>2.0.CO;2

Blimkie, C. J. (1993). Resistance training during preadolescence. Sports Med, 15,389-407. PMID:8341873

Brito, J., Figueiredo, P., Fernandes, L., Seabra, A., Soares, J. M., Krustrup, P., \& Rebelo, A. (2010). Isokinetic strength effects of FIFA's "The 11+" injury prevention training programme. Isokinetics and Exercise Sciences, 18, 211-215. https://doi.org/10.3233/IES-2010-0386

Brito, J., Vasconcellos, F., Oliveira, J., Krustrup, P., \& Rebelo, A. (2014). Short-Term Performance Effects of Three Different Low-Volume Strength-Training Programmes in College Male Soccer Players. Journal of Human Kinetics, 40, 121-128. https://doi.org/10.2478/hukin-2014-0014

Christou, M., Smilios, I., Sotiropoulos, K., Volaklis, K., Pilianidis, T., \& Tokmakidis, S. P. (2006). Effects of resistance trainingon the physical capacities of adolescent soccer players. J. Strength Cond. Res., 20(4), 783-791. https://doi.org/10.1519/R-17254.1

Daneshjoo, A., Mokhtar, A. H., Rahnama, N., \& Yusof, A. (2012). The effects of injury preventive warm-up programs on knee strength ratio in young male professional soccer players. PLoS One, 7, e50979. https://doi.org/10.1371/journal.pone.0050979

Faigenbaum, A. D., Wescott, W. L., \& Micheli, L. J. (1996). The effects of strength training and detraining on children. J Strength Cond, 10, 109-114. https://doi.org/0.1519/1533-4287(1996)010<0109:TEOSTA>2.3.CO;2

Faigenbaum. A. D., Zaichkowsky, L. D., Westcott, W. L., Micheli, L. J., \& Fehlandt, A. F. (1993), The effects of a twice-a-week strength training program on children. Pediatr. Exerc. Sci., 5, 339-346. https://doi.org/10.1123/pes.5.4.339

Falk, B., \& Tenenbaum, G. (1996). The effectiveness of resistance training in children.A meta-analysis. Sports Med., 3 , 176-186. PMID:8883214

Haghighi, A., Moghadasi, M., Nikseresht, A., Torkfar, A., \& Haghighi, M. (2012). Effects of plyometric versus resistance training on sprint and skill performance in young soccer players. European Journal of Experimental Biology, 2(6), 2348-2351. https://doi.org/10.3892/etm.2016.3419 
Hedrick, A. (2000). Training the trunk for improved athletic performance. Strength and Conditioning Journal, 22, 50-61. https://doi.org/10.1519/00126548-200006000-00013

Helgerud, J., Engen, L. C., Wisløff, U., \& Hoff, J.(2001). Aerobic endurance training improves soccer performance. Medicine \& Science In Sports \& Exercise, 1925-1931. PMID:11689745

Hoffman, J. R., Cooper, J., Wendell, M., \& Kang, J. (2004). Comparıson Of Olympıc Vs. Traditional Power Liftıng Trainıng Programs In Football Players, Journal Of Strength And Conditioning Research, 18(1), 129-135. https://doi.org/10.1519/00124278-200402000-00019

Iacono, A. D., Padulo, J., \& Ayalon, M. (2016). Core Stability Training On Lower Limb Balance Strength . Journal Of Sports Sclences, 34(7), 671-678. https://doi.org/10.1080/02640414.2015.1068437

Manolopoulos, E., Papadopoulos, C., Salonıkıdıs, K., Katartzı, E., \& Poluha, S. (2004). Strength Trainıng Effects On Physical Conditioning And Instep Kick Kinematics In Young Amateur Soccer Players Durıng Preseason, Perceptual And Motor Skills, 99, 701-710. https://doi.org/10.2466/pms.99.2.701-710

Marques, M. C., Pereira, A., Reis, I. G., \& Tillaar, R. V. D. (2013). Does an in-Season 6-Week Combined Sprint and Jump Training Program Improve Strength-Speed Abilities and Kicking Performance in Young Soccer Players? Journal of Human Kinetics, 39, 157-166. https://doi.org/10.2478/hukin-2013-0078

Marshall, P. W., \& Murphy, B. A. (2005). Core stability exercises on and off a Swiss ball. Archives of Physical Medicine and Rehabilitation, 86, 242e249. Doi:10.1016/j.apmr.2004.05.004

McCurdy, K. W., Langford, G. A., Doscher, M. W., Wiley, L. P., \& Mallard, K. G. (2005), The effects of short-term unilateral and bilateral lower-body resistance training on measures of strength andpower. Journal of Strength andConditioning Research, 19, 9-15. https://doi.org/10.1519/14173.1

Meylan, C., \& Malatesta, D. (2009). Effects Of In-Season Plyometrıc Tranıng Withın Soccer Practice On Explosive Actions Of Young Players. Journal of Strength and Conditioning Research, 23(9), 2605-2613. https://doi.org/10.1519/JSC.0b013e3181b1f330

Mor, D., \& Christian, V. (1979). The development of a skill test battery to measure general soccer ability. North Carolina Journal of Health and Physical Education, 15.

Nesser, T. W., Huxel, K. C., Tincher, J. L., \& Okado, T. (2008). The relationship between core stability and performance in Division I football players. J. Strength Cond. Res., 22(6), 1750-1754. https://doi.org/10.1519/JSC.0b013e3181874564

Ramsay, J. A., Blimkie, C. J., Smith, K., Garner, S., MacDougall, J., \& Sale, D. G. (1990). Strength training effects in prepubescent boys. Issues and controversies.Med Sci Sports Exerc, 22, 605-614. PMID:2233199

Sedano, S. (2009). The Effects of lower-limb plyometric training on body composition, explosive strength, and kicking speed in female soccerplayers. J. Strength Cond. Res., 23, 1714-1722. https://doi.org/10.1519/JSC.0b013e3181b3f537

Sever, O. (2017). Futbolcularda statik ve dinamik core egzersizlerin Stork denge testine etkisi. Journal of Human Sciences, 14(2), 1781-1791. https://doi.org/10.14687/jhs.v14i2.4440

Stanton, R., Reaburn, P. R., \& Humphries, B. (2004). The effect of short-term Swiss ball training on core stability and running economy. J. Strength Cond. Res., 18, 522-528.

https://doi.org/10.1519/1533-4287(2004)18<522:TEOSSB >2.0.CO;2

Taskin, C. (2016). Effect of Core Training Program on Physical Functional Performance in Female Soccer Players. International Education Studies, 9(5), 115-123. http://dx.doi.org/10.5539/ies.v9n5p115

Tse, M. A., McManus, A. M., \& Masters, R. S. W. (2005). Development and validation of a core endurance intervention program: implications for performance in college-age rowers. J. Strength Cond. Res., 19, 547-552. https://doi.org/10.1519/15424.1

Villarreal, S. E. (2015), Effects of plyometric and sprint training on physical and technical skill performance in adolescent soccer players. J. Strength Cond. Res., 29(7), 1894-1903. https://doi.org/10.1519/JSC.0000000000000838

Yıldızer, G., \& Kirazc1, S. (2017). Effects of core stability on junior male soccer players' balance: randomized control trial. Pamukkale Journal of Sport Sciences, 8(1), 48-62.

\section{Copyrights}

Copyright for this article is retained by the author(s), with first publication rights granted to the journal.

This is an open-access article distributed under the terms and conditions of the Creative Commons Attribution license which permits unrestricted use, distribution, and reproduction in any medium, provided the original work is properly cited. 